\title{
TRANSNEURONAL REGULATION OF TYROSINE HYDROXYLASE EXPRESSION IN OLFACTORY BULB OF MOUSE AND RAT ${ }^{1}$
}

\author{
H. BAKER, ${ }^{*}, 2$ T. KAWANO, $\ddagger$ F. L. MARGOLIS, $\ddagger$ AND T. H. JOH* \\ *Laboratory of Neurobiology, Cornell University Medical College, New York, New York 10021 and $\ddagger$ Department of \\ Physiological Chemistry and Pharmacology, Roche Institute of Molecular Biology, Nutley, New Jersey 07110
}

Received March, 12, 1982; Revised August 3, 1982; Accepted August 3, 1982

\begin{abstract}
Peripheral afferent input regulates the expression of dopaminergic properties in a population of local circuit intrinsic neurons of the rodent olfactory bulb. Lesions of the olfactory receptor neurons produced in the mouse by intranasal irrigation with either $\mathrm{ZnSO}_{4}$ or Triton $\mathrm{X}-100$ and in the rat by surgical deafferentation or axotomy are associated with a decrease in the levels of dopamine (DA), the DA metabolite 3,4-dihydroxyphenylacetic acid (DOPAC), the activity of the enzyme tyrosine hydroxylase (TH), bulb weight and an increase in norepinephrine (NE) levels in the olfactory bulb. The anatomical correlates of the biochemical sequelae of deafferentation of olfactory bulb DA neurons were studied using immunohistochemical techniques to localize TH. Within 3 to 4 weeks all lesions produced a dramatic and uniform reduction in TH staining of the juxtaglomerular DA neurons and their processes which was paralleled by a reduction in DA and DOPAC levels and bulb weight. Seven weeks following reversible chemical lesions produced by Triton X-100, DA and DOPAC levels and tissue weight as well as TH staining in the juxtaglomerular neurons returned to control levels. These observations suggested that DA neurons remained present even when not demonstrable with $\mathrm{TH}$ antibodies. Additional evidence for the continued presence of the DA neurons was the ability of the olfactory bulbs from both lesioned mouse and rat to synthesize DA from exogenously administered L-3,4-dihydroxyphenylalanine ( $l$-DOPA). These data suggested that the decrease in DA levels and TH staining in the olfactory bulb following lesions of the olfactory receptor neurons were produced by transneuronal mechanisms since there was no direct injury of the bulb. Furthermore, the demonstration that following reinnervation, catecholamine synthetic capacity is restored suggests that the juxtaglomerular dopamine neurons remain in the bulb and that afferent receptor input is required for expression of $\mathrm{TH}$ enzyme.
\end{abstract}

Lesions of mouse and rat olfactory epithelium produce degeneration of the afferent olfactory receptor neurons which are associated with profound changes in the olfactory bulb of the levels of dopamine (DA) and norepinephrine (NE) and the rate-limiting enzyme in their biosynthesis, tyrosine hydroxylase (TH) (Nadi et al., 1981; Kawano and Margolis, 1982).

The levels of DA and its metabolite 3,4-dihydroxyphenylacetic acid (DOPAC) and TH activity decrease and NE levels increase following degeneration of the olfactory receptor cells produced in the mouse by intra-

\footnotetext{
' Preliminary reports of these data were presented at the Society for Neuroscience and International Society for Neurochemistry. This work was supported in part by Grant HL18974. We wish to thank Mr. Bill Feig for expert photographic assistance.

${ }^{2}$ To whom correspondence should be addressed at Laboratory of Neurobiology, Cornell University Medical College, 1300 York Avenue, New York, NY 10021.
}

nasal irrigation with either $\mathrm{ZnSO}_{4}$ or Triton X-100 (Nadi et al., 1981) and in the rat by surgical deafferentation (extirpation of the olfactory turbinates) or olfactory nerve axotomy (Kawano and Margolis, 1982). Chemical lesions with $\mathrm{ZnSO}_{4}$ or surgical deafferentation are irreversible, producing permanent reductions in afferent neuron markers such as carnosine, carnosine synthetase, and "olfactory marker protein" (for review see Margolis, $1980 \mathrm{a}, \mathrm{b})$, as well as lasting changes in the catecholamine neuronal markers. In contrast, less drastic chemical lesions of the olfactory epithelium by irrigation with Triton $\mathrm{X}-100$ or olfactory nerve axotomy produce changes in the levels of both the afferent markers and the olfactory bulb catecholamines which are reversible (Nadi et al., 1981; Kawano and Margolis, 1982) as a result of the unique ability of the receptor neurons to regenerate from stem cells and to subsequently reinnervate the olfactory bulb (Harding et al., 1977; Graziadei and Monti-Graziadei, 1978, 1980). 
Olfactory bulb dopamine is concentrated in the periglomerular cell layer (Jaffe and Cuello, 1980; Nadi et al., 1981). Immunohistochemical localization of the dopamine-synthesizing enzymes, tyrosine hydroxylase and dopa decarboxylase (DDC) but not the norepinephrinesynthesizing enzyme, dopamine $\beta$-hydroxylase $(\mathrm{DBH})$ (Halasz et al., 1977, 1981), have shown that both periglomerular cells and some tufted cells are dopaminergic.

Norepinephrine is distributed throughout the bulb but is concentrated in the external plexiform, mitral, and granule cell layers (Jaffe and Cuello, 1980; Nadi et al., 1981; Halasz et al., 1978). The noradrenergic elements have been shown to be limited to centrifugal fibers with no evidence for the presence of cell bodies (Swanson and Hartman, 1975; Fallon and Moore, 1978; Macrides et al., 1981; Broadwell and Jacobowitz, 1976). Since catecholamine-containing elements have not been found in the afferent receptor fiber pathway (Halasz et al., 1978; Macrides et al., 1981), the effects on olfactory bulb dopamine systems resulting from receptor cell ablation are presumed to be the result of transneuronal mechanisms.

These reversible changes in DA levels and TH activity raise several questions. First, is the time course of the changes in the levels of dopamine and its metabolites paralleled by alterations in the immunohistochemical localization of $\mathrm{TH}$ in the bulb; that is, do both $\mathrm{TH}$ enzyme activity and TH protein decline simultaneously? Second, since there are several types of dopamine neurons in the bulb, do the decreases in the amount of DA and in $\mathrm{TH}$ activity occur in all juxtaglomerular DA neurons or only in a certain subpopulation? Also, do the DA concentrations decrease because the neurons are still present but unable to produce $T H$, the rate-limiting enzyme, or do they regenerate? Lastly, are there changes in the NE-containing fibers as is suggested by the increase in levels of NE in the deafferented bulb?

To address these questions, groups of experimental animals were monitored simultaneously for changes in biochemical measurements of catecholamines and for localization of TH by immunohistochemical techniques. The specific time points selected for study were based on detailed time courses reported previously (Nadi et al., 1981; Kawano and Margolis, 1982).

\section{Matcrials and Methods}

\section{Animals}

Retired breeder CD-1 female mice were purchased from Charles River Breeding Laboratories (Wilmington, MA). Eight-week-old female WKY rats were obtained from Taconic Farms. All animals were maintained with food and water ad lihitum on a 12-hr light, 12-hr dark illumination cycle.

\section{Treatments}

Lesions. Unanesthetized mice each were given a single intranasal irrigation (Margolis et al., 1974) with $100 \mu \mathrm{l}$ of one of the following: $0.15 \mathrm{M} \mathrm{NaCl}, 0.7 \%$ Triton $\mathrm{X}-100$ in $0.15 \mathrm{M} \mathrm{NaCl}$, or $0.17 \mathrm{M} \mathrm{ZnSO}_{4}$. Unilateral peripheral surgical deafferentation was produced in 3- to 4-monthold rats (Kawano and Margolis, 1982). In anesthetized rats $(50 \mathrm{mg} / \mathrm{kg}$ of Nembutal, i.p., Abbott Laboratories,) a small hole was drilled through the vomeronasal bone, the olfactory turbinates were dissected out, and the cavity was packed with Gelfoam (The Upjohn Co.). At appropriate times, animals were taken randomly for either biochemical or immunocytochemical staining. In excess of 35 animals were carried through the immunocytochemical procedures.

$l$-DOPA loading. The procedure for $l$-DOPA loading was essentially that described by Lidbrink et al. (1974). Animals received reserpine (Sigma Chemical Co., $2 \mathrm{mg}$ / $\mathrm{kg}$ ) at time zero followed by the decarboxylase inhibitor, RO4-4602 (50 mg/kg), at $18 \mathrm{hr}$. Some animals then received L-3,4-dihydroxyphenylalanine ( $l$-DOPA) $(200 \mathrm{mg}$ / $\mathrm{kg})$ at $18.5 \mathrm{hr}$. All drugs were administered intraperitoneally. Animals were killed at $19.5 \mathrm{hr}$ and catecholamines and their metabolites in the olfactory bulb were measured.

\section{Catecholamines, DOPA, and DOPAC determinations}

Animals were sacrificed by decapitation at various times after surgical or chemical treatment, and olfactory bulbs were dissected, frozen immediately on dry ice, and weighed. Catecholamines, DOPA and DOPAC, were isolated by absorption on alumina and analyzed by high pressure liquid chromatography with electrochenical detection (HPLC-ECD) as previously described (Kawano and Margolis, 1982). In brief, the weighed tissues were homogenized in $400 \mu \mathrm{l}$ of cold $0.1 \mathrm{M} \mathrm{HClO}_{4}$ containing 5 mM sodium metabisulfite and $1 \mathrm{mM}$ EDTA and $10 \mathrm{pmol}$ of dihydroxybenzylamine as the internal standard. After centrifugation, supernatants were transferred to $1.5-\mathrm{ml}$ polyethylene centrifuge tubes and $50 \mathrm{mg}$ of acid-washed alumina were added to each, followed by $1.0 \mathrm{ml}$ of $0.5 \mathrm{M}$ Tris-HCl buffer, $\mathrm{pH}$ 8.6. The tubes were shaken by inversion for $15 \mathrm{~min}$ to allow the catechols to adsorb onto the alumina. Subsequently, the alumina was allowed to settle and the tissue extract was aspirated off. The alumina was washed twice with $4 \mathrm{ml}$ of $0.05 \mathrm{M}$ Tris buffer, transferred to a Pasteur pipette plugged with glass wool, and washed twice with $4 \mathrm{ml}$ of distilled water. The minicolumn was eluted with $100 \mu$ l of $0.1 \mathrm{M}$ perchloric acid/EDTA solution and the catechols were desorbed with $300 \mu \mathrm{l}$ of $0.1 \mathrm{M} \mathrm{HClO}_{4}$. One hundred microliters of this eluate containing the catechols then were injected into the chromatographic system.

HPLC-ECD was performed using a Bioanalytical System model 304 liquid chromatograph equipped with an electrochemical detector. A $25 \times 0.46 \mathrm{~cm}$ stainless steel analytical column packed with $5 \mu \mathrm{m}$ ODS Biophase was used. The mobile phase was $5 \%$ methanol, $0.1 \mathrm{~mm}$ EDTA, $0.08 \mathrm{M}$ monobasic potassium phosphate to which phosphoric acid (1.5 ml/liter) was added to $\mathrm{pH} 2.8$. 1-Octane sulfonic acid ( $30 \mathrm{mg} / \mathrm{liter}$ ) was added as an ion-pairing agent. The flow rate was maintained at $1.5 \mathrm{ml} / \mathrm{min}$. Catechols were oxidized at an applied potential of +0.72 $\mathrm{V}$ vs. $\mathrm{Ag} / \mathrm{AgCl}$ using a glassy carbon electrode. Under these conditions, NE, DOPA, DA, and DOPAC were separated completely with retention times of $4,6,10$, and $16 \mathrm{~min}$, respectively. The internal standard dihydroxybenzylamine eluted at $5.5 \mathrm{~min}$. The response of the ECD was linear in the range from 1 to 1000 pmol injected. Recovery of standards taken through the entire procedure was routinely 70 to $80 \%$. 


\section{Immunohistochemistry}

Both mice and rats were anesthetized with Nembutal ( $50 \mathrm{mg} / \mathrm{kg}$, i.p.) and perfused transcardially for $5 \mathrm{~min}$ with $4 \%$ paraformaldehyde in $0.1 \mathrm{M}$ sodium phosphate buffer, $\mathrm{pH}$ 7.2. Brains were postfixed for $1 \mathrm{hr}$ in the same solution, washed overnight, and infiltrated with $30 \%$ sucrose. The tissue was frozen on dry ice and serial $16-\mu \mathrm{m}$ cryostat sections were collected on gelatin-coated slides. Adjacent sections were stained with either cresyl violet, a Nissl stain, or antibodies to tyrosine hydroxylase.

The peroxidase-antiperoxidase (PAP) method of Sternberger et al. (1970) as previously described (Teitelman et al., 1979) was used. Briefly, sections were incubated with: $(a) 0.25 \%$ Triton X-100 in $0.1 \mathrm{M}$ Tris-saline buffer ( $\mathrm{pH} \mathrm{7.6)}$ for $15 \mathrm{~min}$ and washed for $5 \mathrm{~min}$ in the same buffer, $(b) 3 \%$ goat serum in buffer for $30 \mathrm{~min}$ and washed in buffer, $(c)$ antibodies to tyrosine hydroxylase (1/500 dilution) overnight and washed in buffer containing $1 \%$ goat serum, $(d)$ goat anti-rabbit IgG (1/50 dilution, Miles Laboratories, Elkhart, IN) and washed in buffer, $(e)$ rabbit PAP (1/50 dilution prepared in our laboratories) and washed in buffer, or $(f)$ diaminobenzidine $(50 \mathrm{mg} / 100 \mathrm{ml})$ with $0.01 \% \mathrm{H}_{2} \mathrm{O}_{2}$ for $6 \mathrm{~min}$. Sections were washed in water, dehydrated through graded alcohols, and coverslipped with Permount. The procedure for preparation of the antibodies to $\mathrm{TH}$ as well as the criteria to judge their specificity have been described previously (Joh et al., 1973).

\section{Materials}

All chemicals, unless otherwise stated, were reagent grade; RO4-4602 was a gift of Hoffman-La Roche, Inc.

\section{Results}

Normal anatomy of DA- and NE-containing elements in the olfactory bulb. As was previously described in the rat (Halasz et al., 1977) and confirmed here in both the rat (Figs. 1 and 2) and the mouse (Figs. 3 and 4), large numbers of TH-stained neurons were found in the periglomerular region of the olfactory bulb. The majority of these neurons were of the small periglomerular cell type. Some larger neurons, probably tufted cells, also were stained. A few stained neurons also were found in the external plexiform layer (EPL) and occasionally in the mitral cell layer (Fig. 5). A dense plexus of fibers was present within and between the glomeruli with some fibers traversing the EPL. In the mitral and internal granule cell layers, thin varicose fibers were seen, the latter probably noradrenergic in nature (Fig. 6). Terminals but not neuronal cell bodies were observed in the accessory olfactory bulb (not illustrated).

TH staining following surgical or chemical lesions. Following $\mathrm{ZnSO}_{4}$ lesions in the mouse (Fig. $3 B$ ), $\mathrm{TH}$ staining in juxtaglomerular neurons and their processes was reduced dramatically (compare Fig. $3, A$ and $B$ ) with virtual elimination of $\mathrm{TH}$-stained neurons. To determine if the reduction in staining was uniform throughout the

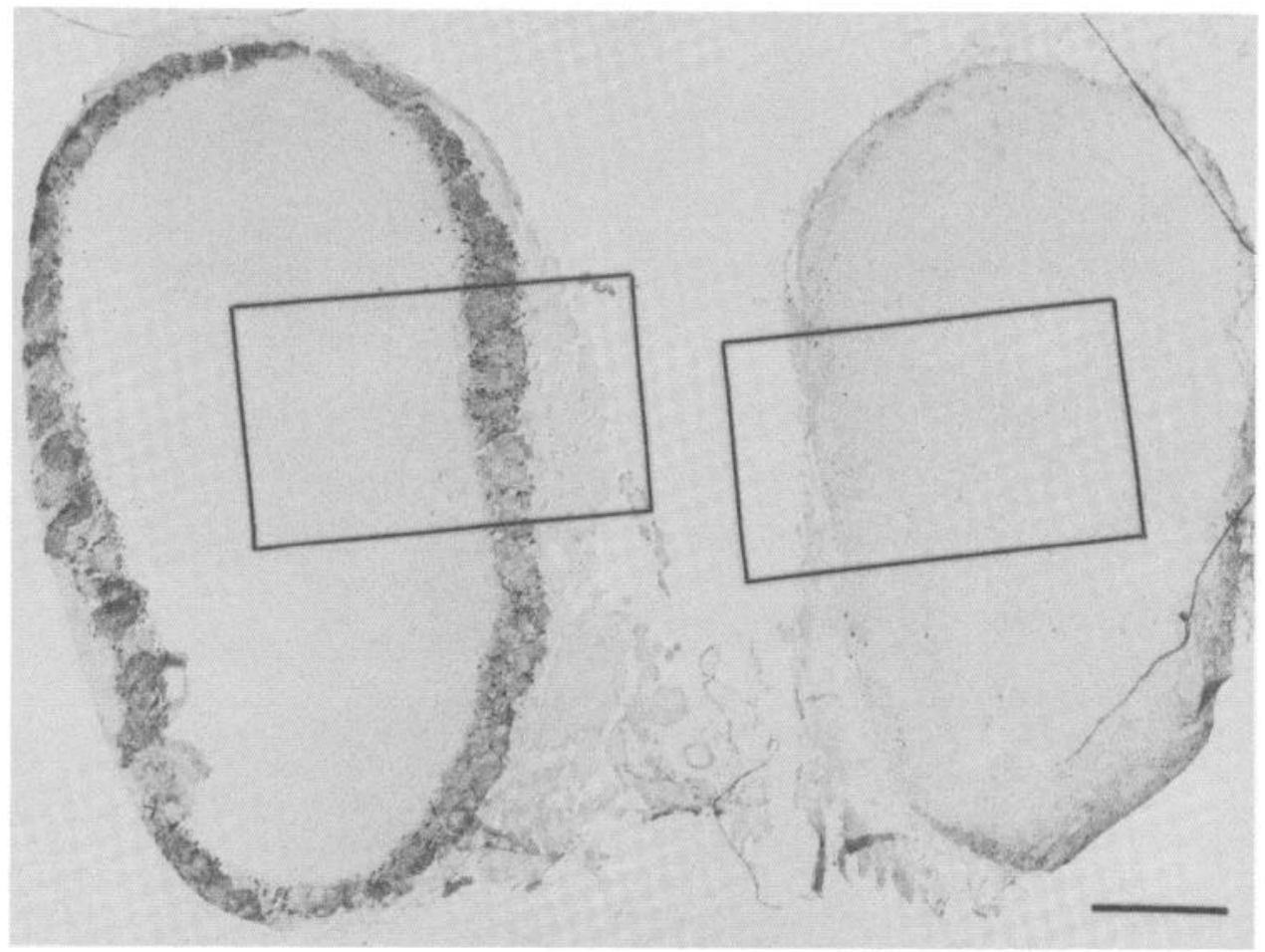

Figure 1. Reduced olfactory bulb tyrosine hydroxylase after olfactory receptor cell lesions in the rat. Low power photomicrograph of a transverse section of olfactory bulbs taken from a rat with a unilateral surgical lesion of the olfactory epithelium. The section was stained with antibodies to tyrosine hydroxylase. The bulb on the left or unlesioned side exhibited intense staining in the periglomerular layer in neurons thought to be dopaminergic. Staining in the right bulb or lesioned side was reduced dramatically. The lesioned bulb was also significantly smaller than the control bulb. The areas within the rectangles are shown at higher magnification in Figure 2. Bar, $500 \mu \mathrm{m}$. 

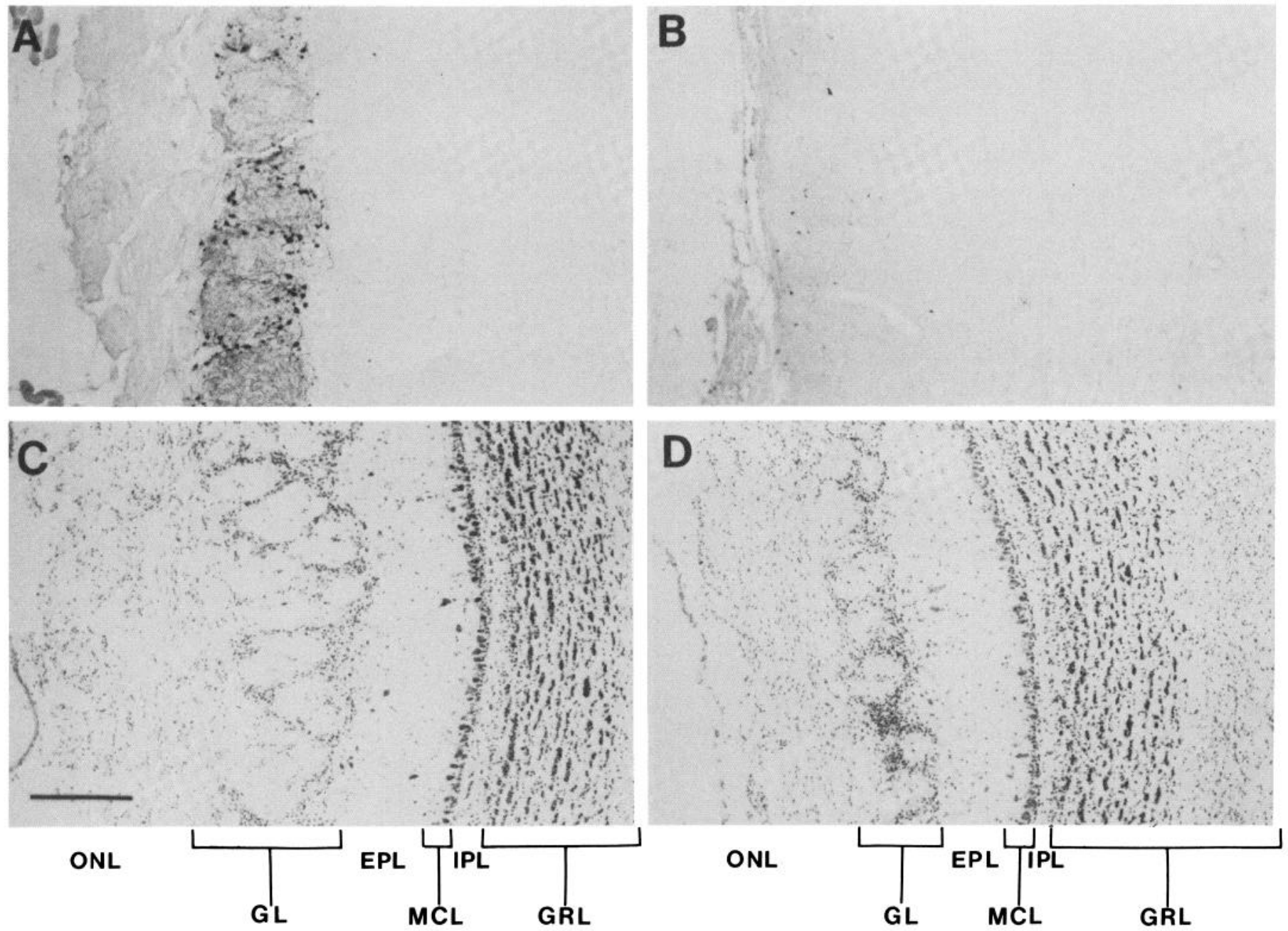

Figure 2. Comparison of lesion-induced changes in TH staining and olfactory bulb morphology in the rat. Adjacent sections of a rat olfactory bulb were stained either with antibodies to tyrosine hydroxylase or with cresyl violet. The unilateral surgical lesion produced a decrease in tyrosine hydroxylase staining in both cell bodies and their processes (compare $A$ and $B$ ). The decrease in the size of the olfactory bulb seen in Figure 1 can be attributed to a reduction in the size of the glomeruli and the thickness of the glomerular layer $(G L)$ as illustrated by the cresyl violet-stained sections where $C$ is from the control side and $D$ is from the lesioned side. The width of the external plexiform layer $(E P L)$ also was reduced in the lesioned bulb. The extent of the lesion was indicated by the degeneration of the olfactory nerve layer $(O N L)$. No changes in the internal plexiform (IPL), mitral cell (MCL), or granule cell $(G R L)$ layers were observed $B a r, 200 \mu \mathrm{m}$.

length of the olfactory bulb, serial sections of the bulb were obtained. One out of every three sections was stained with antibodies to $\mathrm{TH}$ with the adjacent sections utilized for the Nissl stain. In all regions examined, a similar massive reduction in staining was observed. The few remaining stained cells were, in general, randomly scattered throughout the bulb with no indication of a specific cell type predominating. Occasional small groups of stained cells remained. These were always in the midline of the olfactory bulb and are thought to reflect regions of the olfactory epithelium which escaped the application of the $\mathrm{ZnSO}_{4}$ solution. TH staining did remain in the processes and terminals of the internal granule cell, mitral cell, and external plexiform layers (Fig. 6).

The size of the olfactory bulb was reduced in lesioned mice. The Nissl stain revealed that the reduction in size of the bulb was attributable to a decrease in the thickness of both the olfactory nerve and glomerular layers (com- pare Fig. 4, $A$ and $B$ ) which accompanied the decrease in TH staining.

Three weeks following Triton X-100 lesions in the mouse, TH staining was reduced significantly with only a few positively stained periglomerular neurons and processes remaining (Fig. $3 C$ ). Staining at this time was similar to that observed in $\mathrm{ZnSO}_{4}$-treated mice. Adjacent Nissl-stained sections demonstrated that there also was a decrease in the size of the glomeruli of the same magnitude as that produced by $\mathrm{ZnSO}_{4}$ lesions (Fig. $4 \mathrm{C}$ ). The availability of serial sections allowed sampling of all regions of the olfactory bulb. As in the $\mathrm{ZnSO}_{4}$-treated mice, the reduction in staining was uniform throughout the bulb. In animals observed 49 days following an identical Triton X-100 lesion, TH staining had returned to or was above normal levels and was similar to that in control mice (Fig. $3 D$ ).

Surgically generated deafferentation of the olfactory 

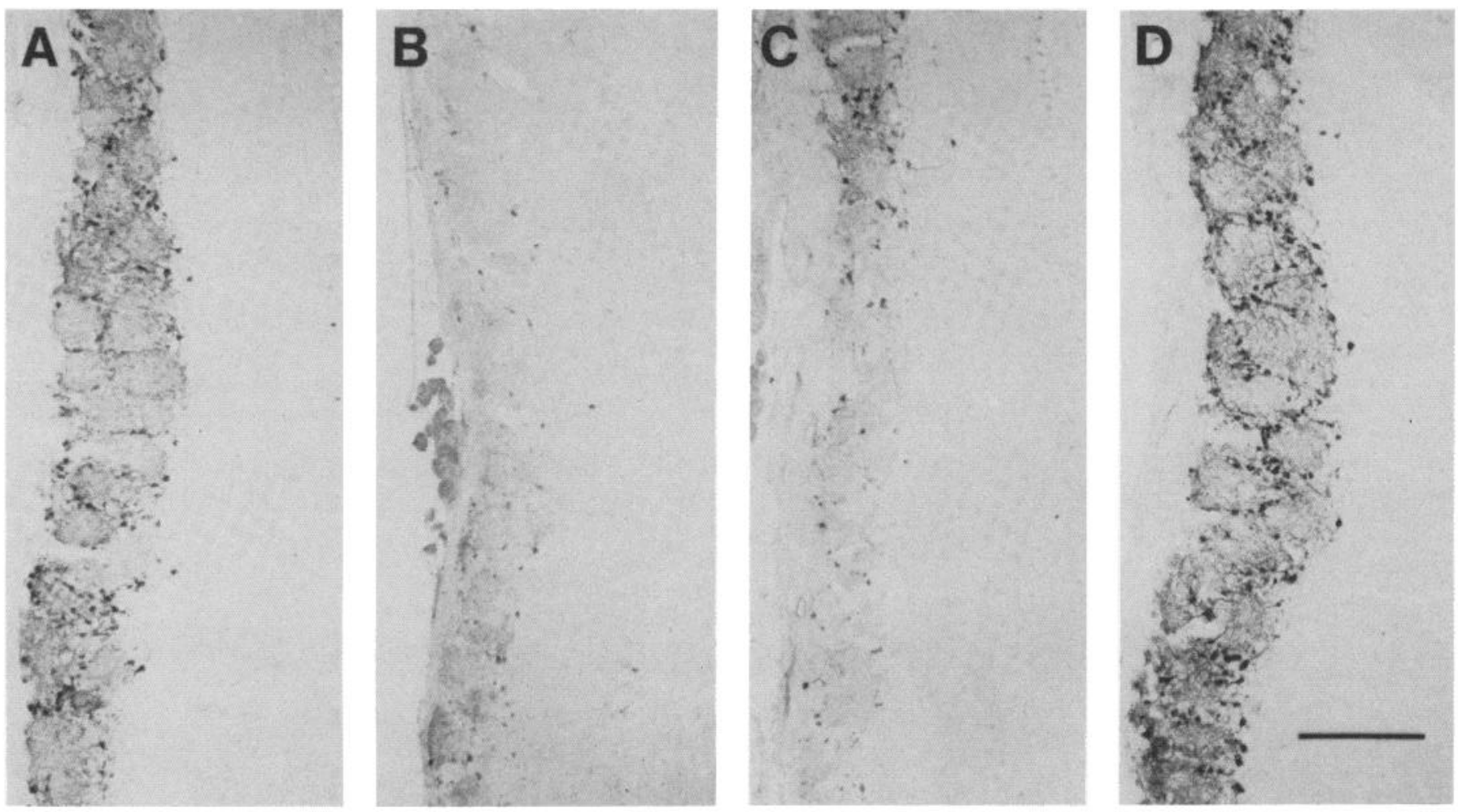

Figure 3. $\mathrm{ZnSO}_{4^{-}}$and Triton $\mathrm{X}-100$-induced alteration in tyrosine hydroxylase staining in the mouse olfactory bulb. A comparison of staining with antibodies to $\mathrm{TH}$ in the mouse olfactory bulb 21 days following intranasal infusion with $0.15 \mathrm{M} \mathrm{NaCl}$ $(A), 0.17 \mathrm{M} \mathrm{ZnSO}_{4}(B)$, or $0.7 \%$ Triton X-100 $(C)$ and 49 days following infusion with the same dose of Triton X-100 $(D)$. In the control mouse $(A)$, staining with $\mathrm{TH}$ antibodies was the same as seen in the rat with labeled cells predominantly in the periglomerular layer. Staining also was contained in a dense plexus of fibers which coursed between and within the glomeruli. In mice, 21 days after lesions with either $\mathrm{ZnSO}_{4}(B)$ or Triton X-100 $(C)$, staining was greatly reduced in both the periglomerular neurons and their processes. All regions of the olfactory bulb exhibited a similar reduction in staining. The reduction in the number of stained neurons produced by Triton X-100 was reversible as illustrated in $D$ with staining returning to control levels 49 days following irrigation with this agent. Bar, $200 \mu \mathrm{m}$.
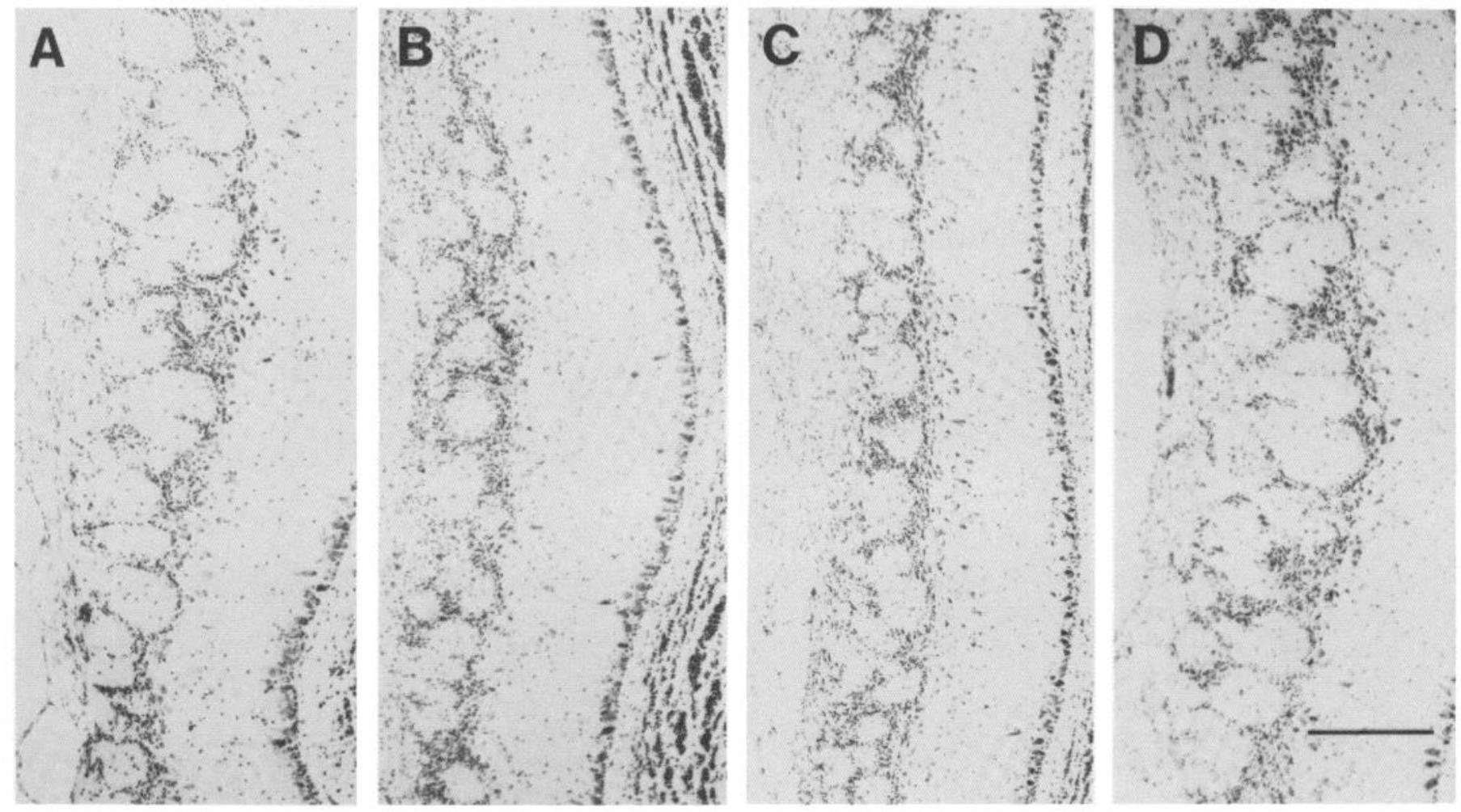

Figure 4. $\mathrm{ZnSO}_{4}$ - and Triton $\mathrm{X}-100$-induced alteration in olfactory bulb morphology in the mouse. Sections adjacent to those in Figure 3 were stained with cresyl violet to demonstrate the decrease in the width of the glomerular layer and the size of the glomeruli 21 days following intranasal irrigation with either $0.17 \mathrm{M} \mathrm{ZnSO}_{4}(B)$ or $0.7 \%$ Triton X-100 $(C)$ when compared to control mice $(A)$. The morphology in sections from mice examined 49 days following treatment with Triton X-100 $(D)$ was similar to that in control mice $(A)$ illustrating that full recovery can occur after reinnervation by the olfactory receptor cells. $B a r, 200 \mu \mathrm{m}$. 
bulb of the rat decreased TH immunocytochemical staining at 3 to 4 weeks to a similar extent as chemical lesions in the mouse (Figs. 1 and 2). As in the mouse, TH staining was so extensively reduced that no individual cell type was spared in the glomerular layer. The decrease in staining was accompanied by a large reduction in the size of the olfactory bulb (Fig. 1), resulting for the most part from the degeneration of the afferent olfactory receptor neuronal input and thus a shrinkage of the glomeruli (compare Fig. 2, $B$ and $D$ ).

Effects of lesions on catecholamine levels in the olfac- tory bulb. In mice, 21 days following intranasal irrigation with either $\mathrm{ZnSO}_{4}$ or Triton X-100 (Table I), similar reductions (2- to 3 -fold as compared to saline-treated controls) in DA levels were observed. DOPAC levels also were reduced (3- to 4 -fold), as was tissue weight ( $30 \%$ in $\mathrm{ZnSO}_{4}$-treated mice and $15 \%$ in Triton X-100-treated mice). By 49 days post-lesion in the Triton X-100-treated mice, DA and DOPAC levels and bulb weight had increased significantly and were comparable to control values. In contrast, at both 30 days and 90 days after the $\mathrm{ZnSO}_{4}$ lesion (Table II), DA levels remained at less than

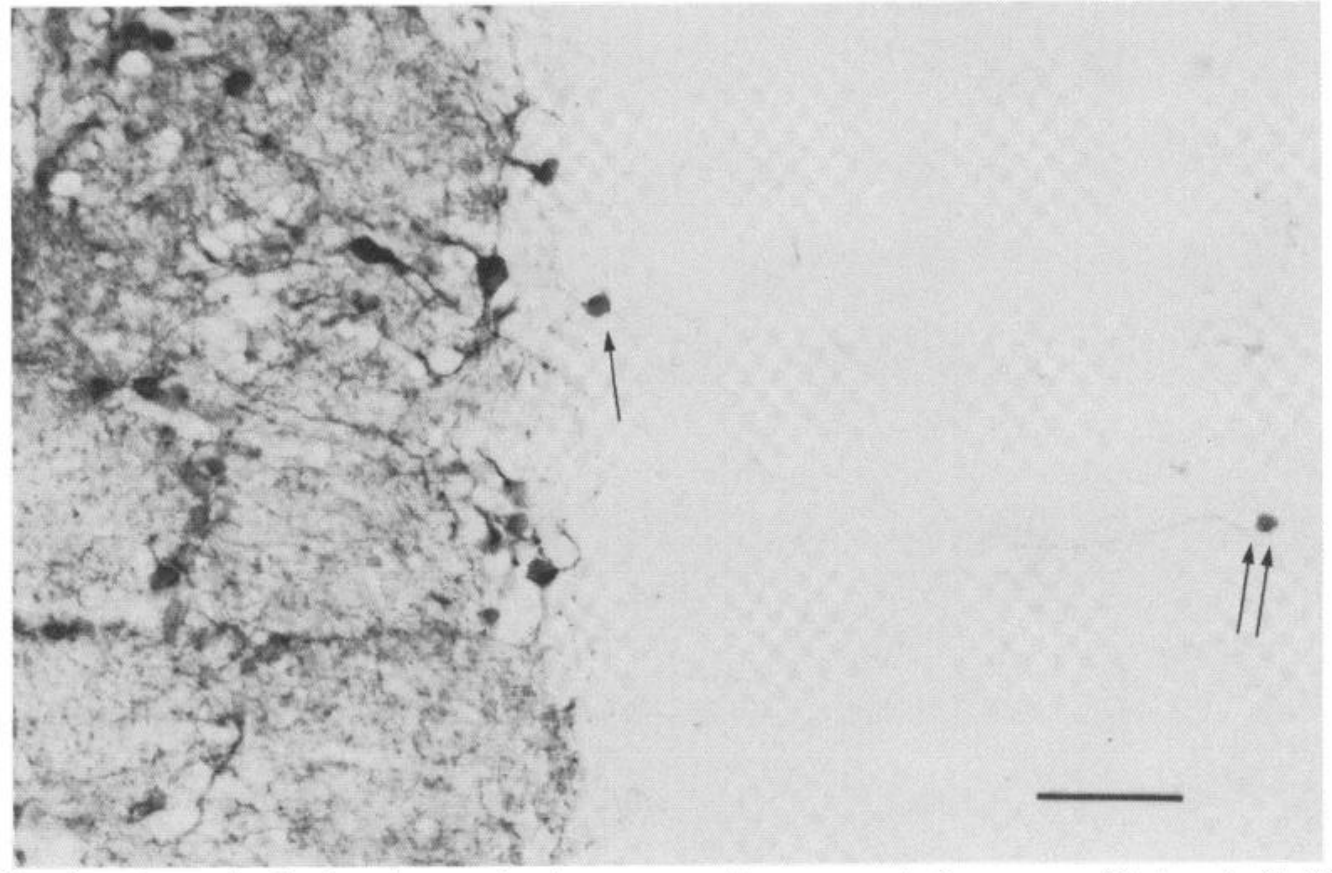

Figure 5. Distribution of tyrosine hydroxylase-stained neurons and processes in the mouse olfactory bulb. TH staining in the mouse olfactory bulb illustrating the variation in size of stained neurons and the presence of stained cells in other than the periglomerular region. Stained cells occasionally were seen in the external plexiform layer (single arrow) as well as the mitral cell layer (double arrows). Processes of periglomerular neurons coursed both between as well as within the glomeruli. Bar, $50 \mu \mathrm{m}$.

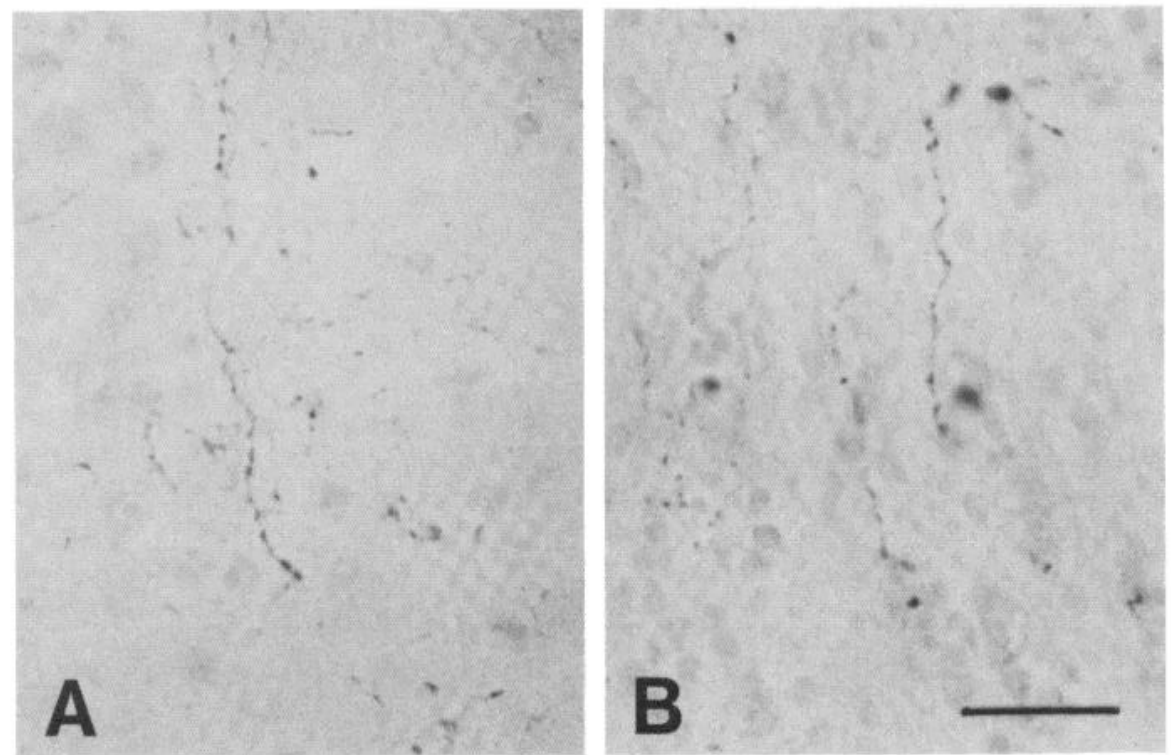

Figure 6. Lack of change in TH-stained processes in the olfactory bulb of $\mathrm{ZnSO}_{4}$-treated mice. Processes, presumably noradrenergic in nature, were found in the granule cell layer of both control $(A)$ and $\mathrm{ZnSO}_{4}$-treated $(B)$ mice. The number of fibers did not appear to differ between the two treatment groups indicating that lesions with $\mathrm{ZnSO}_{4}$ did not alter the centrifugal noradrenergic input to the olfactory bulb. Bar, $25 \mu \mathrm{m}$. 
TABLE I

Influence of chemical and surgical deafferenting lesions on catecholamines in rat and mouse olfactory bulb ${ }^{a}$

\begin{tabular}{|c|c|c|c|c|c|c|c|}
\hline Species and Treatment & $\begin{array}{c}\text { Time after } \\
\text { lesions }\end{array}$ & $\mathbf{N}$ & NE & DA & DOPAC & Tissue weight & TH Staining ${ }^{b}$ \\
\hline \multicolumn{8}{|l|}{ Mouse } \\
\hline $\mathrm{ZnSO}_{4}$ & 21 & 3 & $2388 \pm 222^{c}$ & $381 \pm 85^{c}$ & $96 \pm 16^{c}$ & $15.1 \pm 0.7^{c}$ & \pm \\
\hline Triton X-100 & 21 & 3 & $1674 \pm 171$ & $485 \pm 51^{c}$ & $139 \pm 16^{c}$ & $19.2 \pm 0.6^{d}$ & 1 \\
\hline Triton X-100 & 49 & 3 & $1971 \pm 239^{e}$ & $1227 \pm 248$ & $515 \pm 114^{d}$ & $21.3 \pm 1.4$ & 3 \\
\hline Lesioned side & 28 & 3 & $2558 \pm 294^{d}$ & $101 \pm 33^{c}$ & $55 \pm 22^{c}$ & $24.1 \pm 1.1^{\mathrm{c}}$ & \pm \\
\hline
\end{tabular}

${ }^{a}$ Values are means $\pm \mathrm{SD}$.

${ }^{b} \mathrm{TH}$ staining is on a scale from 0 to 3 with \pm indicating occasional patches of staining.

${ }^{c} p<0.001$ when compared to saline control or unlesioned side by the Student's $t$ test (two tailed).

${ }^{d} p<0.05$ when compared to saline control or unlesioned side by the Student's $t$ test (two tailed).

e $p<0.01$ when compared to saline control or unlesioned side by the Student's $t$ test (two tailed).

TABLE II

Influence of l-DOPA loading on catecholamine levels in normal and deafferented olfactory bulb of mouse and rat ${ }^{a}$

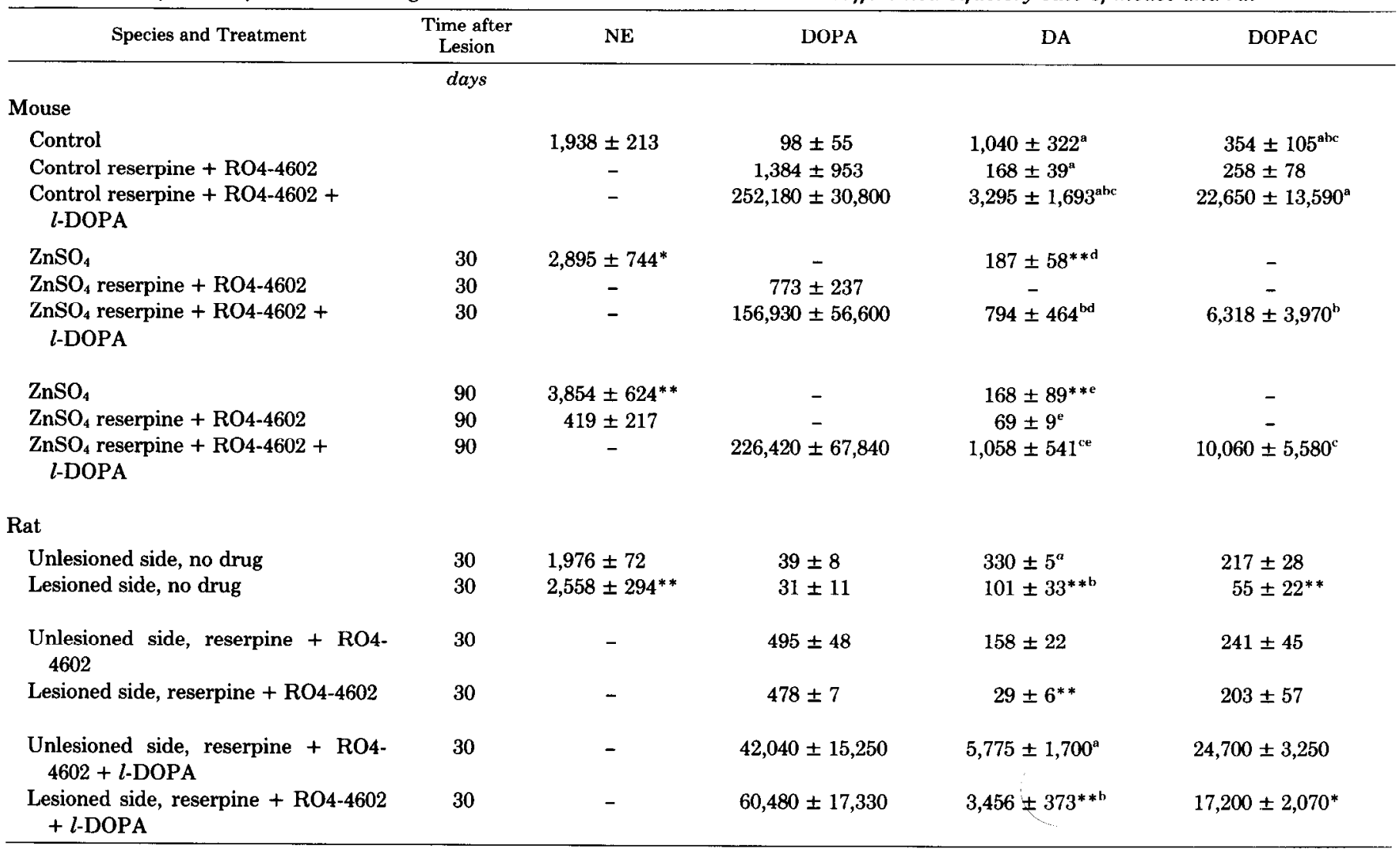

${ }^{a}$ All data are expressed as pmol/g of tissue, mean $\pm \mathrm{SD}, N=3$ to 4 . Statistical evaluations were by the Student's two tailed $t$ test. A dash in the table indicates the compound was undetectable by the HPLC-ECD. For the mouse, comparisons of data for control and $\mathrm{ZnSO}_{4}$-lesioned mice withont drug treatment are indicated by asterisks $\left({ }^{*} p<0.05 ;{ }^{* *} p<0.01\right)$. Selected statistical comparisons were performed for data from $l$ DOPA-loaded mice and values in a given column with the same letter superscript differ by at least $p<0.05$. For the rat, statistical comparisons were carried out between companion sets of data from lesioned, and unlesioned animals and are indicated by asterisks ( ${ }^{*} p<0.05$; ${ }^{* *} p<0.01$ ). Statistical comparisons between selected treatment groups are indicated by letter superscripts. Those with the same letter superscript differ by at least $p<0.01$.

$20 \%$ of control values with no indication of return toward pre-lesion levels. In the $\mathrm{ZnSO}_{4}$-treated mice, NE levels consistently were elevated relative to unlesioned controls (Tables I and II).

The effects of surgical lesions in the rat were similar to those produced by chemical lesions in the mouse. At 28 days following unilateral surgical deafferentation, a 3- fold reduction in DA levels and a 4-fold decrease in DOPAC levels were observed in the lesioned bulb. Tissue weight also was reduced significantly by deafferentation. As in the mouse, NE levels were elevated significantly. The DA, DOPAC, and NE levels in the unlesioned olfactory bulb were not different from those observed in unoperated rats (unpublished observation). 
The amount of staining with the antibody to $\mathrm{TH}$ closely followed the tissue levels of DA. Using a rating scale of 0 to 3 ( 0 , no staining; 3 , maximal staining), control tissue in both the mouse and the rat was rated $3, \mathrm{ZnSO}_{4}$ treated mice or rats with surgical lesions were rated 0 or \pm , indicating only small patches of staining. Triton X100-treated mice at 21 days were rated 1 and at 49 days post-lesion, 3 (Table I).

Catecholamine metabolism following l-DOPA administration. If the periglomerular and lufted DA neurons, although no longer demonstrable with antibodies against $\mathrm{TH}$, were still present in the bulb and contained the enzyme DOPA decarboxylase, then they should be able to synthesize DA from exogeneously supplied $l$-DOPA. In olfactory bulbs of control animals, $l$-DOPA administration has permitted the visualization of a subpopulation of juxtaglomerular neurons by catecholamine histofluorescence (Lidbrink et al., 1974; Lichtensteiger, 1966; Halasz et al., 1978). Therefore, lesioned and control mice and rats were administered $l$-DOPA to determine if the bulbs could still synthesize dopamine.

In both lesioned and unlesioned mice, the DA content of the olfactory bulbs increased following $l$-DOPA administration $(p<0.05)$. Either 1 or 3 months following $\mathrm{ZnSO}_{4}$ treatment, lesioned mice exhibited a similar qualitative pattern of responses to the administration of $l$ DOPA as did unlesioned mice, although the magnitudes of the effects were different. The level of DA in $l$-DOPAloaded $\mathrm{ZnSO}_{4}$-lesioned mice rose to that seen in unlesioned, untreated mice at both times after lesion (no statistically significant difference) but was only 25 to $30 \%$ of that seen in $l$-DOPA-loaded unlesioned mice (Table II). DOPAC and DOPA concentrations also increased in the $\mathrm{ZnSO}_{4}$-lesioned mice after DOPA loading. Unilateral olfactory deafferentation in the rat followed by $l$-DOPA administration produced effects qualitatively similar to those observed in the mouse (Table II). Thus, in both the lesioned and unlesioned rat bulb, $l$-DOPA loading results in a large increase in the level of DA. The level of DA achieved is higher $(p<0.05)$ in the unlesioned compared to the lesioned bulb. On the lesioned and unlesioned sides, DOPA and DOPAC levels also were increased in $l$-DOPA-treated rats. In both species, the level of NE in the lesioned bulbs is higher than is observed in unlesioned bulb (compare Tables I and II) and, in nearly all cases, reserpine reduces NE to below detection limits.

\section{Discussion}

The normal anatomy of the olfactory bulb in both the rat and the mouse was very similar. As had been previously described in the rat (Halasz et al., 1977, 1978, 1981), a large number of neurons stained with antibodies to $\mathrm{TH}$ were found surrounding the glomeruli. These neurons, which have been reported to be dopaminergic, occasionally were found outside the glomerular layer in both the external plexiform and the mitral cell layers. A dense plexus of fibers was found within and between the glomeruli with processes extending into the EPL and the mitral cell layers. These fibers previously have been reported to be dopaminergic (Halasz et al., 1977). The thin varicose fibers which were found in the internal granule cell and plexiform layers presumably represent the extrinsic noradrenergic input to the olfactory bulb (Swanson and Hartman, 1975; Fallon and Moore, 1978; Macrides et al., 1981; Broadwell and Jacobowitz, 1976; Halasz et al., 1978).

Chemical and surgical lesions of the olfactory epithelium in both the rat and the mouse initially produced the same changes in the olfactory bulb. DA and DOPAC concentration, biochemical markers of DA neurons, were reduced dramatically in both species. The changes in the biochemical indices were followed closely by the staining of the neurons with antibodies to TH. After lesion, the dopamine neuronal cell bodies which normally surrounded the glomeruli were, for the most part, not demonstrable with the antibody, indicating that $\mathrm{TH}$ protein disappears as well as TH activity. No single type of DA neuron appeared to be spared following deafferentation, with all types of neurons in the juxtaglomerular position losing the ability to be stained by TH antibody. In those animals in which a few patches of residual stained neurons were seen, they were largely located in the medial aspects of the olfactory bulb and probably represented regions in which the deafferentation produced by the lesions of the olfactory epithelium was incomplete.

Staining in the fibers in and between the glomeruli also was reduced dramatically, as would be expected if the DA neurons no longer stained. Fiber staining in the other layers did not appear to decrease. Since these are the presumed noradrenergic fibers, the lack of change in staining is in agreement with the proposal that the increase in $\mathrm{NE}$ concentration in $\mathrm{ZnSO}_{4}$-lesioned mice ( $\mathrm{Nadi}$ et al., 1981) and surgically lesioned rats (Kawano and Margolis, 1982) reflects the decrease in the size of the bulb rather than any major change in noradrenergic innervation (i.e., NE content per bulb is unaltered).

Nissl staining of sections adjacent to those stained for TH indicated that the glomeruli were reduced in size. However, it was not clear if the number of juxtaglomerular granule cells was reduced. In fact, the cell density in this region appeared to have increased. This increase in cell density could have resulted from the fact that the glomerulus was reduced in size, thus bringing the cells closer together. However, since not all juxtaglomerular cells are dopaminergic (Ribak et al., 1977; Hoffman et al., 1979; Halasz et al., 1979; Davis et al., 1982), and the proportion of DA neurons to other neuronal cell types is not known, the loss of a subpopulation of neurons might not be easily discerned.

The lack of staining in the dopamine neurons suggested that the cells might have degenerated. Thus, the question remained, did the lack of staining of the DA neurons with the antibodies to $\mathrm{TH}$ indicate cell loss or did these neurons simply stop producing the rate-limiting neurotransmitter synthetic enzyme in a transneuronal response to peripheral deafferentation? A decrease in the ability of a neuron to produce neurotransmitter synthetic enzyme has been demonstrated in noradrenergic (Ross et al., 1975), dopaminergic (Gilad and Reis, 1979), and cholinergic systems (Wooten et al., 1978), following a direct axon lesion.

In an attempt to answer this question, Triton $\mathrm{X}-100$ was used to produce lesions of the olfactory epithelium, since intranasal irrigation with this agent produces a reversible lesion of the olfactory neuroepithelium (Nadi 
et al., 1981). Triton X-100 (at the concentration employed) seems to destroy only mature receptor cells, permitting immature stem cells to differentiate and produce new axons which reinnervate the olfactory bulb. The previously characterized time course of the olfactory receptor cell degeneration/regeneration phenomenon was used to select appropriate time points at which to study TH immunohistochemical staining (Nadi et al., 1981; Kawano and Margolis, 1982). The three time points chosen were: (1) pretreatment, (2) when $\mathrm{TH}$ aclivity was at a minimum, and (3) when activity had returned to control levels. Three weeks following a Triton X-100 lesion, TH staining in the mouse was reduced to the same extent as it was in $\mathrm{ZnSO}_{4}$-treated mice. However, 7 weeks after Triton X-100 treatment, at a time when olfactory receptor neuron regeneration was completed and the levels of DA and DOPAC were at control levels, TH staining was at or above control levels. The apparent "overshoot" in TH staining could represent a phenomenon similar to that observed in the ventral tegmental DA system during development where $\mathrm{TH}$ activity reaches values $25 \%$ above control levels (Baker et al., 1982).

As another indication of the continued presence of the DA neurons in the olfactory bulb, even in the absence of tyrosine hydroxylase enzyme, the ability of lesioned bulbs to synthesize DA from exogenously administered $l$ DOPA was examined. The administration of $l$-DOPA as the DA precursor bypasses the TH enzyme step, as the enzyme DOPA decarboxylase (DDC), the second enzyme in the DA biosynthetic pathway, directly decarboxylates the $l$-DOPA to form DA. The possibility that DDC may remain in these cells in the absence of $\mathrm{TH}$ is consistent with the finding that some cells, such as the APUD cells of the pancreas, have DDC but not TH (Teitelman et al., 1981). We found that, following reserpine, RO4-4602, and $l$-DOPA administration, $\mathrm{ZnSO}_{4}$-lesioned mice could synthesize DA to the same extent as untreated unlesioned mice, but they exhibited less ability to syntheize DA than treated unlesioned mice. In the rat, the lesioned bulb also was able to synthesize DA and metabolize it to DOPAC but at a reduced level as compared to the similarly treated unlesioned bulbs. Thus, these experiments indicate that the olfactory bulb can produce DA in the absence of demonstrable $\mathrm{TH}$, albeit at a reduced capacity. Alternatively, the synthetic capability could arise from a pool of DDC outside the DA neurons as, for example, in the cerebral inicrovasculature (Melamed et al., 1980) or the serotonin or NE axons and terminals in the olfactory bulb (Margolis, 1981). However, consistent with our interpretation is the recent demonstration in the rat (Margolis et. al., 1982) that the lesioned olfactory bulb contains $65 \%$ of the unlesioned level of DDC activity as well as juxtaglomerular neurons which stain immunohistochemically for DDC in the lesioned bulb. These observations indicate that DDC is still present in the lesioned bulb in a population of cells which formerly also contained TH.

One additional line of evidence for the continued presence of the DA neurons in the olfactory bulb was the demonstration that there was not reduction in DA uptake in bulbs from $\mathrm{ZnSO}_{4}$-treated mice (Margolis et al., 1974). Therefore, at least three functions of the DA neuron, DA uptake, synthesis, and DDC staining, are retained by the deafferented bulb indicating that these neurons may not degenerate.

The mechanism by which a lesion of the peripheral afferents to the olfactory bulb results in selective loss of DA, TH activity, and TH immunocytochemical staining of the juxtaglomerular cells of the bulb is unknown. Although afferent receptor cells do synapse on tufted and periglomerular cell dendrites (White, 1973; Pinching and Powell, 1971; Garrido et al., 1978), evidence for specific contacts with dopaminergic elements has not been published. However, during ontogeny, TH immunocytochemical staining in the olfactory bulb (Specht et al., 1981) appears only after the olfactory receptor neuron axons reach the bulb (Hinds and Hinds, 1976; Farbman and Margolis, 1980; Monti-Graziadei et al., 1980). Furthermore, following lesions to the peripheral afferents, the intial decline and, where appropriate, the subsequent return of DA levels and TH activity parallel the changes in biochemical markers associated with the olfactory receptor afferents; that is, olfactory marker protein and carnosine content (Nadi et al., 1981). In addition, lesions of the centrifugal afferents to the bulb which cause major declines of NE levels and choline acetyltransferase activities in the olfactory bulb do not influence DA levels (Macrides et al., 1981), arguing that the phenomenon we are studying here is not simply a general metabolic response to lesion of inputs to the bulb. Taken together, these various observations imply some form of neuronal, or possibly synaptic, interaction between the afferent olfactory fibers and the juxtaglomerular DA neurons.

We conclude that lesions of the olfactory epithelium which produce degeneration of the afferent receptor input to the olfactory bulb alter the ability of periglomerular and tufted DA neurons to produce the neurotransmitter-synthesizing enzyme, $\mathrm{TH}$, and compromise neurotransmitter synthesis and metabolism by these cells. These effects are produced transneuronally, since no direct lesion of the DA neuron is made. Furthermore, when reinnervation occurs, the changes in synthetic capacity are reversed, suggesting that deafferented neurons may remain in a quiescent state which requires afferent input for tyrosine hydroxylase expression.

\section{References}

Baker, H., T. H. Joh, and D. J. Reis (1982) Time of appearance during development of differences in nigrostriatal tyrosine hydroxylase activity in two inbred mouse strains. Dev. Brain Res., 4: 157-165.

Broadwell, R. D., and D. M. Jacobowitz (1976) Origins of the ipsilateral centrifugal fibers to the main and accessory olfactory bulbs in rabbit and rat. A histochemical fluorescence and retrograde peroxidase study. J. Comp. Neurol. 170: 321346.

Davis, B. J., G. D. Burd, and F. Macrides (1982) Localization of met-enkephalin, substance $P$ and somatostatin immunoreactivities in the main olfactory bulb of the hamster. J. Comp. Neurol. 204: 377-383.

Fallon, J. H., and R. Y. Moore (1978) Catecholamine innervation of the basal forebrain. III. Olfactory bulb, anterior olfactory nuclei, olfactory tubercle and periform cortex. J. Comp. Neurol. 180: 533-544.

Farbman, A. I., and F. L. Margolis (1980) Olfactory marker protein during ontogeny: Immunohistochemical localization. Dev. Biol. 74: 205-215. 
Garrido, M., R. Garcia Del Moral, M. J. Gayoso, G. Sanchez, and L. Diaz-Flores (1978) A study of the glomeruli of the olfactory bulb and other neuronal elements related to them. Morfol. Norm. Patol. 1A: 167-204.

Gilad, G., and D. J. Reis (1979) Collateral sprouting in central mesolimbic dopamine neurons: Biochemical and immunocytochemical evidence of changes in the activity and distribution of tyrosine hydroxylase in terminal fields and in cell bodies of A10 neurons. Brain Res. 160: 17-36.

Graziadei, P. P. C., and G. A. Monti-Graziadei (1978) The olfactory system: A model for the study of neurogenesis and axon regeneration in mammals. In Neuronal Plasticity, C. W. Cotman, ed., pp. 131-153, Raven Press, New York.

Graziadei, P. P. C., and G. A. Monti-Graziadei (1980) Neurogenesis and neuron regeneration in the olfactory system of mammals. III. Deafferentation and reinnervation of the olfactory bulb following section of the fila olfactoria in rat. J. Neurocytol. 9: 145-162.

Halasz, N., A. Ljungdahl, T. Hokfelt, O. Johansson, M. Goldstein, D. Park, and P. Biberfeld (1977) Transmitter histochemistry of the rat olfactory bulb. I. Immunohistochemical localization of monoamine synthesizing enzymes. Support for intrabulbar periglomerular dopamine neurons. Brain Res. 126: 455-474.

Halasz, N., A. Ljungdahl, and T. Hokfelt (1978) Transmitter histochemistry of the rat olfactory bulb. II. Fluorescence, histochemical, autoradiographical and electron microscopic localization of monoamines. Brain Res. 154: 253-271.

Halasz, N., A. Ljungdahl, and T. Hokfelt (1979) Transmitter histochemistry of the rat olfactory bulb. III. Autoradiographic localization of (3H) GABA. Brain Res. 167: 221-240.

Halasz, N., O. Johansson, T. Hokfelt, A. Ljungdahl, and M. Goldstein (1981) Immunohistochemical identifications of two types of dopamine neuron in the rat olfactory bulb as seen by serial sectioning. J. Neurocytol. 10: 251-259.

Harding, J., P. P. C. Graziadei, G. A. Monti-Graziadei, and F. L. Margolis (1977) Denervation in the primary olfactory pathway of mice. IV. Biochemical and morphological evidence for neuronal replacement following nerve section. Brain Res. 132: 11-28.

Hinds, J. W., and P. L. Hinds (1976) Synapse formation in the mouse olfactory bulb. Quantitative studies. J. Comp. Neurol. 169: 15-39.

Hoffman, G. E., B. J. Davis, and F. Macrides (1979) LHRH perikarya send axons to the olfactory bulb in the hamster. Soc. Neurosci. Abstr. 5: 528.

Jaffè, E. H., and A. C. Cuello (1980) The distribution of catecholamines, glutamate decarboxylase and choline acetyltransferase in layers of the rat olfactory bulb. Brain Res. 186: 232-237.

Joh, T. H., C. Geghman, and D. J. Reis (1973) Immunochemical demonstration of increased accumulation of tyrosine hydroxylase protein in sympathetic ganglia and adrenal medulla elicited by reserpine. Proc. Natl. Acad. Sci. U. S. A. 70: 27672771.

Kawano, T., and F. L. Margolis (1982) Transsynaptic regulation of olfactory bulb catecholamines in mice and rats. J. Neurochem., 39: 342-348.

Lichtensteiger, W. (1966) Uptake of norepinephrine in periglomerular cell of the olfactory bulb of the mouse. Nature 210: 955-956.

Lidbrink, P., G. Jonsson, and K. Fuxe (1974) Selective reserpine-resistant accumulation of catecholamines in central dopamine neurons after DOPA administration. Brain Res. 67: 439-456.

Macrides, F., B. J. Davis, W. M. Youngs, N. S. Nadi, and F. L. Margolis (1981) Cholinergic and catecholaminergic afferents to the olfactory bulb in the hamster: A neuroanatomical, biochemical and histochemical investigation. J. Comp. Neurol. 203: 495-514.

Margolis, F. L. (1980a) Carnosine: An olfactory neuropeptide.
In Role of Peptides in Neuronal Function, J. L. Barker and T. G. Smith, Jr., eds., pp. 545-572, Marcel Dekker, Inc., New York.

Margolis, F. L. (1980b) A marker protein for the olfactory chemoreceptor neuron. In Proteins of the Nervous System, R. A. Bradshaw and D. Schneider, eds., pp. 59-84, Raven Press, New York.

Margolis, F. L. (1981) Neurotransmitter biochemistry of the mammalian olfactory bulb. In Biochemistry of Taste and Olfaction, R. Cagan and M. Kare, eds., pp. 369-394, Academic Press, New York.

Margolis, F. L., N. Roberts, D. Ferriero, and J. Feldman (1974) Denervation in the primary olfactory pathway of mice: Biochemical and morphological effects. Brain Res. 81: 469-483.

Margolis, F. L., H. Baker, T. Kawano, V. Albert and T. H. Joh (1982) Do juxtaglomerular cells die after peripheral deafferentation of the rat olfactory bulb? Soc. Neurosci. Abstr., in press.

Melamed, E., F. Hefti, and R. J. Wurtman (1980) Decarboxylation of exogenous L-DOPA in rat striatum after lesions of the dopaminergic nigrostriatal neurons: The role of striatal capillaries. Brain Res. 198: 244-248.

Monti-Graziadei, G. A., R. S. Stanley, and P. P. C. Graziadei (1980) The olfactory marker protein in the olfactory system of the mouse during development. Neuroscience 5: 12391252.

Nadi, N. S., R. Head, M. Grillo, J. Hempstead, N. GrannotReisfeld, and F. L. Margolis (1981) Chemical deafferentation of the olfactory bulb: Plasticity of the levels of tyrosine hydroxylase, dopamine and norepinephrine. Brain Res. 213: $365-371$

Pinching, A. J., and T. P. S. Powell (1971) The neuropil of the glomeruli of the olfactory bulb. J. Cell Sci. 9: 347-377.

Ribak, C. E., J. E. Vaughn, K. Saito, R. Barber, and E. Roberts (1977) Glutamate-decarboxylase localization in neurons of the olfactory bulb. Brain Res. 126: 1-18.

Ross, R. A., T. H. Joh, and D. J. Reis (1975) Reversible changes in the accumulation and activities of tyrosine hydroxylase and dopamine- $\beta$-hydroxylase in neurons of nucleus locus coeruleus during the retrograde reaction. Brain Res. 92: 5772.

Specht, L. A., V. M. Pickel, T. H. Joh, and D. J. Reis (1981) Light-microscopic immunocytochemical localization of tyrosine hydroxylase in prenatal rat brain. I. Early Ontogeny. J. Comp. Neurol. 199: 233-253.

Sternberger, L. A., P. H. Hardy, Jr., J. J. Cuculis, and H. B. Meyer (1970) The unlabeled antibody enzyme method of immunocytochemistry. Preparation and properties of soluble antigen-antibody complex (horseradish peroxidase-antihorseradish peroxidase) and its use in identification of spirochetes. J. Histochem. Cytochem. 18: 315-333.

Swanson, L. W., and B. K. Hartman (1975) The central adrenergic system. An immunofluorescence study of the location of cell bodies and their efferent connections in the rat utilizing dopamine- $\beta$-hydroxylase as a marker. J. Comp. Neurol. 163: 467-503.

Teitelman, G., H. Baker, T. H. Joh, and D. J. Reis (1979) Appearance of synthesizing enzymes during development of rat sympathetic nervous system: Possible role of tissue environment. Proc. Natl. Acad. Sci. U. S. A. 76: 509-513.

Teitelman, G., D. J. Reis, and T. H. Joh (1981) Transformation of catecholaminergic precursors into glucagon (A) cells in the mouse embryonic pancreas. Proc. Natl. Acad. Sci. U. S. A. 78: 5225-5229.

Wooten, G. F., D. H. Park, and D. J. Reis (1978) Immunochemical demonstration of reversible reduction in choline acetyltransferase concentration in rat hypoglossal nucleus after hypoglossal nerve transection. Nature 275: 324-325.

White, E. L. (1973) Synaptic organization of the mammalian olfactory glomerulus: New findings including an intraspecific variation. Brain Res. 60: 299-313. 